\title{
Fatores associados à infecção pelo vírus da estomatite vesicular em equídeos no estado do Rio Grande do Norte, Brasil*
}

\section{Factors associated with infection by the vesicular stomatitis virus in equines in the state of Rio Grande do Norte, Brazil}

\author{
Taile Katiele Souza de Jesus, ${ }^{* *}$ Diogo Diógenes Medeiros Diniz, ${ }^{* *}$ Leandro Lamartine Lopes Rocha, ${ }^{* *}$ \\ José Wilton Pinheiro Júnior, ${ }^{* *}$ Eliana de Stefano, ${ }^{* * *}$ Adriana Hellmeister de Campos Nogueira Romaldini, ${ }^{* \star *}$ Huber Rizzo*
}

\begin{abstract}
Resumo
Objetivou-se investigar a presença do Vírus da Estomatite Vesicular (VEV) e seus fatores de risco para ocorrência e disseminação da enfermidade em equídeos das mesorregiões Leste e Oeste Potiguar do estado do Rio Grande do Norte, Brasil. Foram analisadas pela técnica de virusneutralização, 809 amostras sanguíneas de equídeos provenientes de noventa propriedades de dezesseis municípios Potiguares durante os meses de julho de 2018 a fevereiro de 2019. Os fatores de riscos associados ao VEV foram avaliados por meio de questionário epidemiológico e os dados submetidos a análise estatística no programa IBM SPSS Statistics versão $21.0 \mathrm{com}$ nível de confiança de $95 \%$. Posteriormente, todas as variáveis estatisticamente significantes foram submetidas a análise de regressão de Poisson. A soroprevalência de anticorpos anti-VEV foi 24,6\% (199/809), sendo 3,2\% (13/402) de soropositivos na mesorregião Leste e 45,7\% (186/407) na do Oeste Potiguar. Com relação aos sorotipos, observou-se uma prevalência de 3,8\% (31/809) e 24,5\% (198/809) para Indiana 2 e 3 respectivamente, com 15,1\% (30/198) de coinfecção. Equídeos criados na mesorregião Oeste, em propriedades que não realizam quarentena e onde os animais enfermos são mantidos no rebanho, foram consideradas fatores predisponentes a infecção pelo VEV. Esses resultados demonstram a circulação do VEV em equídeos no Rio Grande do Norte, com destaque ao Oeste Potiguar, e sendo necessário a aplicação de medidas sanitárias que impeçam introdução e disseminação do vírus ente as espécies susceptíveis, principalmente em condições climáticas favoráveis para a sua manutenção, no ambiente de criação e pastagens.
\end{abstract}

Palavras-chave: cavalos, doenças vesiculares, manejo sanitário, virusneutralização, sorotipo Indiana.

\begin{abstract}
This study aimed to investigate the presence of Vesicular stomatitis virus (VSV) and risk factors for its occurrence and dissemination in equines from the Eastern and Western mesoregions of the state of Rio Grande do Norte, Brazil. Blood samples were analyzed, by Serum Virus Neutralization Assay, from 809 animals belonging to 90 properties distributed in sixteen municipalities from July 2018 to February 2019. Risk factors were assessed using an epidemiological questionnaire. Data were submitted to statistical analysis using the software IBM SPSS Statistics, version 21.0 with a 95\% confidence level. Also, all statistically significant variables were subjected to Poisson regression analysis. The occurrence of anti-VSV antibodies was $24.6 \%$ (199/809) with 3.2\% (13/402) and 45.7\% $(186 / 407)$ of seropositivity in the Western and Eastern mesoregion, respectively. Regarding serotypes, there were an occurrence of 3.8\% (31/809) and 24.5\% (198/809) for Indiana 2 and 3, respectively, and 15.1\% (30/198) of co-infection for both. Equines kept of the Western mesoregion, on properties that do not quarantine, and where sick animals are kept in the herd, were considered risk factors for LVV infection. These results demonstrate the presence of VSV in equines in Rio Grande do Norte, with emphasis on Oeste Potiguar, and that sanitary measures must be adopted to prevent the introduction and viral spreading among susceptible species, especially due to favorable climatic conditions for the maintenance of VSV in the breeding and pasture environment.
\end{abstract}

Keywords: horses, vesicular diseases, Indian, sanitary management, serum neutralization.

\section{Introdução}

A Estomatite Vesicular (EV) é uma doença infectocontagiosa viral, de caráter zoonótico, com ocorrência em ruminantes, equídeos, porcinos e algumas espécies silvestres. $O$ Vírus da Estomatite Vesicular (VEV) pertence à família
Rhabdoviridae, gênero Vesiculovirus, e apresenta dois sorotipos imunologicamente distintos, a cepa New Jersey (VEV-NJ) e Indiana (VEV-IN) a qual ainda é classificada em três subtipos, Indiana 1 ou cepa clássica (VEV-IN 1), Indiana 2, COCAL ou Argentina (VEV-IN 2) e Indiana 3 ou Alagoas (VEV-IN 3) (RozoLopez et al., 2018).

*Recebido em 19 de agosto de 2020 e aceito em 10 de março de 2021.

**Universidade Federal Rural de Pernambuco, Departamento de Medicina Veterinária, CEP 52171-900, Recife, PE, Brasil. E-mail: hubervet@gmail.com. Autor para correspondência.

***Instituto Biológico de São Paulo, Laboratório de Viroses Bovídeos, São Paulo, SP, Brasil. 
A EV é autolimitante de curta duração, com baixa taxa de morbidade e mortalidade, no entanto, relevante por se tratar de uma zoonose e interferir no bem-estar animal devido à formação de vesículas com consequentes erosões e ulcerações em narinas, cavidade bucal e banda coronária dos cascos. Essas lesões dificultam a ingestão de alimento e a locomoção, além de servir de porta de entrada para infecções secundárias, como mastite, principalmente em éguas durante a amamentação (Rozo-Lopez et al., 2018; Urie et al., 2018).

A infecção pelo VEV em equídeos é endêmica nas Américas, sendo o VEV-IN a cepa encontrada e associada a surtos na América do Sul (De Stefano et al., 2002). O primeiro isolamento do VEV no Brasil ocorreu em 1964 no estado de Alagoas em epitélio oral de equinos com lesões, sendo que, devido sua diferença antigênica em relação aos subtipos Indiana 1 e 2, foi classificado como Indiana 3 ou Alagoas. Nesse período também foram relatados casos de humanos com sintomatologia clínica da enfermidade (De Stefano et al., 2002). Levantamentos sorológicos na região Nordeste foram realizados nos estados do Ceará, Paraíba, Maranhão e Pernambuco com ocorrências variando entre 8,7\% (4/46) e 100\% (6/6) (De Stefano et al., 2002; Arruda et al., 2015; Lunkes et al., 2016).

A epidemiologia e a patogênese da EV ainda não estão bem esclarecidas, devido as diferentes vias de transmissão em potencial do vírus. Sabe-se que inclui vetores biológicos (mosquitos, moscas negras e moscas de areia), vetores mecânicos (alimentos contaminados, fômites, aerossóis) e o contato direto com animais infectados (Rozo-Lopez et al., 2018).

A presença da enfermidade resulta em perdas econômicas devido as restrições comerciais internacionais e de participação em feiras, exposições, competições dentre outras (Rozo-Lopez et al., 2018; Urie et al., 2018), por apresentar semelhança clínica com a Febre Aftosa e outras doenças vesiculares de animais biungulados (Arruda et al., 2015).

Por ser economicamente importante e com consequências relevantes para a saúde pública, objetivou-se, investigar a ocorrência de anticorpos e fatores associados na infecção de equinos pelo VEV nas mesorregiões Leste e Oeste Potiguar do estado do Rio Grande do Norte, Brasil.

\section{Material e métodos}

A pesquisa foi desenvolvida no estado do Rio Grande do Norte, localizado na região Nordeste do Brasil (latitude $-5^{\circ} 45^{\prime} 0 \mathrm{~S}$, longitude $-36^{\circ} 30^{\prime} 0$ O), composto por 167 municípios distribuídos em 8.510.820.623 $\mathrm{km}^{2}$, divididos em quatro mesorregiões (Oeste, Central, Agreste e Leste Potiguar). Possui extensa faixa litorânea e condições climáticas que variam de tropical úmido no litoral leste, a semiárido nas demais regiões (IBGE, 2019).

Para o estudo foram selecionados apenas municípios das mesorregiões Leste e Oeste Potiguar, que possuíam população mínima de quinhentos equinos registrados no Instituto de Defesa e Inspeção Agropecuária do Rio Grande do Norte (IDIARN). Considerando um efetivo de 65.345 equídeos (IBGE, 2017), prevalência esperada de $50 \%$, nível de confiança de $95 \%$ e erro estatístico de $5 \%$ (Thrusfield, 2007), foi determinada a partir do programa estatístico Epilnfo 3.5.2, uma amostragem mínima de 384 animais a serem analisados em cada mesorregião. As amostras séricas foram colhidas de todos os equídeos acima de seis meses de idade das propriedades do estudo, que foram selecionadas de acordo com a disponibilidade dos criadores em permitir a colheita de material biológico para análise.

Entre agosto de 2018 e fevereiro de 2019, foram visitadas noventa propriedades de dezesseis municípios (Figura 1) localizados nas mesorregiões Oeste e Leste Potiguar, onde obteve-se amostras sanguíneas de 809 equídeos (786 equinos, dezessete muares e seis asininos) por venopunção da jugular, com sistema de colheita a vácuo em tubos do tipo Vacutainer ${ }^{\circledR}$ sem anticoagulante, identificadas e acondicionadas sob refrigeração em caixa térmica para transporte a Universidade Federal Rural de Pernambuco. As amostras foram centrifugadas a $3.000 \mathrm{rpm}$ durante dez minutos, para obtenção de soro, que foi armazenado em tubos de $2 \mathrm{ml}$ do tipo Eppendorf ${ }^{\otimes} \mathrm{e}$ acondicionados a $-20^{\circ} \mathrm{C}$ até o processamento do teste sorológico.

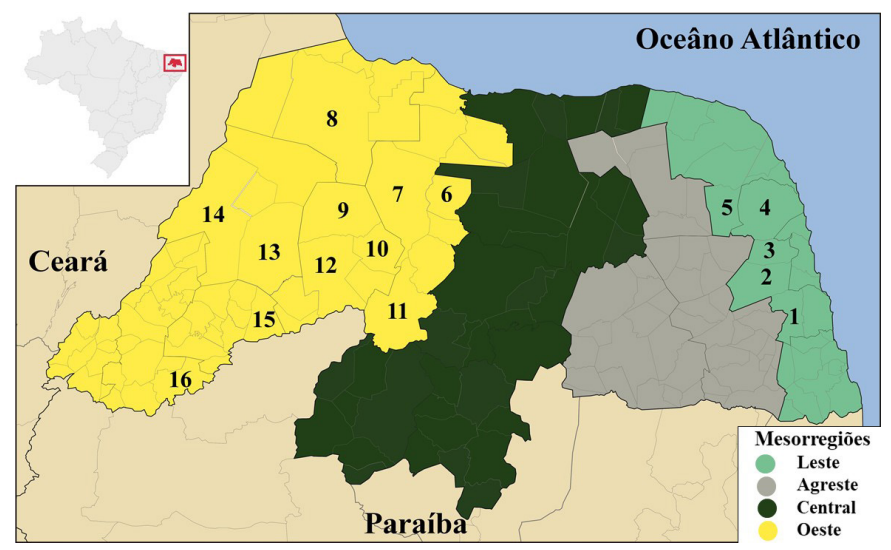

Figura 1: Mapa do Rio Grande do Norte, Brasil, dividido em suas quatro mesorregiões indicando numericamente os municípios onde foram realizadas as colheitas de sangue de equídeos para realização de diagnóstico por virusneutralização para Estomatite Vesicular. Mesorregião Leste Potiguar: 1-São José de Mipibú, 2-Macaíba, 3-São Gonçalo do Amarante, 4-CearáMirim e 5-Taipú. Mesorregião Oeste Potiguar: 6-Ipanguacu, 7-Assu, 8-Mossoró, 9-Upanema, 10-Paraú, 11-Jucurutu, 12-Campo Grande, 13-Caraúbas, 14-Apodi, 15-Patu e 16-Alexandria.

O diagnóstico sorológico do VEV foi realizado no Laboratório de Viroses de Bovídeos do Instituto Biológico de São Paulo, pela técnica de virusneutralização em placas de fundo plano de 96 cavidades, utilizando 1000 TCID $_{50}$ do VEV-IN e células VERO (OIE, 2018). Foram realizadas diluições seriadas das amostras de soro e controles positivo e negativo iniciando-se em 1/4 (diluição final 1/8 após a mistura soro/vírus). Em seguida, adicionou-se o mesmo volume da suspensão viral do Indiana 2 e 3 contendo 1000 TCID50/25uL e incubou-se a $37^{\circ} \mathrm{C}$ por sessenta minutos para permitir a neutralização. Posteriormente, foi adicionada a suspensão de células VERO na concentração de $3 \times 10^{5}$ células $/ \mathrm{mL}$ em todas as placas e incubou-se por 48 a 72 horas a $37^{\circ} \mathrm{C}$ em uma atmosfera de $5 \%$ de $\mathrm{CO}_{2}$ para verificação ou não de citopatotoxidade. Foram considerados positivas as amostras com título igual ou superior a 1/32 (log 1,5).

Para análise de fatores de risco foi aplicado questionário epidemiológico investigativo contendo perguntas relacionadas ao animal, ambiente e as formas de manejo sanitário da propriedade, com intuito de coletar dados relevantes associados a infecção pelo VEV.

As frequências absolutas e relativas foram obtidas a partir de análise descritiva dos dados, enquanto a avaliação dos fatores 
de risco associados à infecção pelo VEV, através da análise univariada das variáveis pelo teste de Qui-quadrado de Pearson e Exato de Fisher, quando necessário. Os dados extraídos foram submetidos a análise de regressão utilizando o modelo robusto de Poisson considerando como variável dependente o resultado reagente ou não reagente obtido no teste de virusneutralização. Dessa forma, as variáveis independentes ou explanatórias consideradas no modelo, foram aquelas que apresentaram significância estatística $p<0,05$ (Hosmer e Lemeshow, 1987) com intervalo de confiança (IC) de $95 \%$, utilizando o programa IBM SPSS Statistics versão 21.0 para todas as análises.

A pesquisa foi desenvolvida mediante aprovação pelo Comitê de Ética no Uso de Animais (CEUA) da Universidade Federal Rural de Pernambuco, sob o número de protocolo 100/2018.

\section{Resultados e discussão}

A prevalência de equídeos soropositivos à infecção por VEV-IN foi de 24,6\% (199/809), sendo 3,2\% (13/402) (IC95\% = 0,015$0,05)$ procedentes da mesorregião Leste e $45,7 \%(186 / 407)$ do Oeste Potiguar, com 64,4\% (58/90) (IC95\% = 0,41-0,51) de propriedades apresentando ao menos um animal sororeagente. Considerando seus subtipos observou-se valor nulo para VEV-IN 1, 3,8\% (31/809) para VEV-IN 2 e 24,5\% (198/809) para VEV-IN 3, com 15,1\% (30/198) de coinfecção.

Levantamento sorológico realizado na região Nordeste em equinos, bovinos e suínos, demonstrou uma alta circulação do vírus, com ocorrência de 91,5\% (300/328) de positivos (Allende e Germano, 1993), enquanto estudos recentes nessa região apontam variações na ocorrência de anticorpos anti-VEV IN 3, com 87,3\% (317/363), 65,7\% (109/166), 45,4\% (124/273) e 8,7\% (4/46) de soropositivos nos estados do Ceará, Rio Grande do Norte, Paraíba e Pernambuco respectivamente (Lunkes et al., 2016), além de seis (100\%) equinos positivos, para o mesmo sorotipo, no Maranhão (Arruda et al., 2015). Levantamentos em outras regiões, apresentaram taxas bem abaixo das encontradas no Rio Grande do Norte, com 0,9\% (9/1.011) e 4,4\% (78/1.767) de soropositivos para VEV-IN 3 no Rio Grande do Sul e em Goiás/Distrito Federal (Lunkes et al., 2016).

Os protótipos do VEV-IN que foram ocasionalmente isolados no Brasil apresentam ocorrências distintas, sendo o VEV-IN 3 o subtipo mais associado a surtos na região Nordeste, enquanto o tipo 2 é relatado em outras regiões do país e Argentina (Cargnelutti et al., 2014). Essa maior ocorrência de casos no Nordeste, pode ser devido ao padrão sazonal da EV, que é mais observada nos meses de verão e estações chuvosas, que associado as vias de transmissão da enfermidade e as características climáticas e de criação da região, possibilitam a manutenção dos vetores com consequente propagação do vírus (Rozo-Lopez et al., 2018).

No Brasil não há relatos de infecção pelo VEV-NJ provavelmente devido ao clima, uma vez que ele é comumente encontrado em regiões temperadas, sendo reportado surtos na América Central, norte do México e sul dos Estados Unidos da América (EUA) (Urie et al., 2018).

$\mathrm{Na}$ análise univariada dos dados, observamos que todas as varáveis de interesse e consideradas como fatores de risco, foram estatisticamente significativas com base no valor de $p$ $<0,05$, a exceção do fator sexo (Tabela 1).
Tabela 1: Análise dos fatores de risco associadas à infecção pelo Vírus da Estomatite Vesicular em equídeos oriundos de criações do Leste e Oeste Potiguar, Rio Grande do Norte, Brasil (2018-2019)

\begin{tabular}{|c|c|c|c|}
\hline Variáveis & $\mathbf{N}$ & Soropositivos & Valor $p$ \\
\hline \multicolumn{4}{|l|}{ Mesorregião } \\
\hline Leste Potiguar & 402 & $13(3,23 \%)$ & \\
\hline Oeste Potiguar & 407 & $186(45,7 \%)$ & 0,000 \\
\hline \multicolumn{4}{|l|}{ Sexo } \\
\hline Macho & 518 & $128(24,7 \%)$ & \multirow{2}{*}{0,496} \\
\hline Fêmea & 291 & $71(24,4 \%)$ & \\
\hline \multicolumn{4}{|l|}{ Espécie } \\
\hline Equino & 786 & $190(24,2 \%)$ & \multirow{3}{*}{0,006} \\
\hline Asinino & 06 & - & \\
\hline Muar & 17 & $9(52,9 \%)$ & \\
\hline \multicolumn{4}{|l|}{ Exploração } \\
\hline Esporte & 465 & $151(32,5 \%)$ & \multirow[t]{5}{*}{0,000} \\
\hline Lazer & 108 & $29(26,9 \%)$ & \\
\hline Reprodução & 07 & - & \\
\hline Trabalho & 97 & $11(11,3 \%)$ & \\
\hline Reprodução/Esporte & 132 & $8(6,1 \%)$ & \\
\hline \multicolumn{4}{|l|}{ Sistema de criação } \\
\hline Intensivo & 259 & $30(11,6 \%)$ & \multirow{3}{*}{0,000} \\
\hline Extensivo & 81 & $25(30,9 \%)$ & \\
\hline Semi-intensivo & 469 & $144(30,7 \%)$ & \\
\hline \multicolumn{4}{|l|}{ Área } \\
\hline Urbana & 175 & $33(19,9 \%)$ & \\
\hline Peri-urbana & 73 & $8(10,9 \%)$ & \multirow{2}{*}{0,000} \\
\hline Rural & 561 & $158(28,2 \%)$ & \\
\hline \multicolumn{4}{|l|}{ Pasto alagado } \\
\hline Sim & 165 & $70(42,4 \%)$ & \multirow[t]{2}{*}{0,000} \\
\hline Não & 644 & $129(20,0 \%)$ & \\
\hline \multicolumn{4}{|l|}{ Tipo de cocho } \\
\hline Individual & 617 & $116(18,8 \%)$ & \multirow{2}{*}{0,000} \\
\hline Coletivo & 192 & $83(43,2 \%)$ & \\
\hline \multicolumn{4}{|l|}{ Realiza quarentena } \\
\hline Sim & 62 & $07(11,3 \%)$ & \multirow{2}{*}{0,005} \\
\hline Não & 747 & $192(25,7 \%)$ & \\
\hline \multicolumn{4}{|l|}{$\begin{array}{l}\text { Animais doentes } \\
\text { mantidos no rebanho }\end{array}$} \\
\hline Sim & 736 & $190(25,8 \%)$ & \multirow{2}{*}{0,005} \\
\hline Não & 73 & $09(12,3 \%)$ & \\
\hline \multicolumn{4}{|l|}{ Desinfeta as instalações } \\
\hline Sim & 135 & $14(10,4 \%)$ & \multirow{2}{*}{0,000} \\
\hline Não & 674 & $185(27,5 \%)$ & \\
\hline
\end{tabular}


Tabela 2: Análise de regressão de Poisson dos fatores de risco associados à infecção pelo Vírus da Estomatite Vesicular em equídeos criados no Leste e Oeste Potiguar, Rio Grande do Norte, Brasil (2018-2019)

\begin{tabular}{llll}
\hline Variáveis & Valor de $\boldsymbol{p}$ & RP & IC \\
\hline $\begin{array}{l}\text { Mesorregião } \\
\text { Leste Potiguar }\end{array}$ & & & \\
$\begin{array}{l}\text { Oeste Potiguar } \\
\text { Realiza quarentena }\end{array}$ & 0,000 & 1,358 & $1,300-1,419$ \\
$\quad$ Sim & 0,000 & 1,169 & $1,103-1,239$ \\
$\quad$ Não & & & \\
Animais doentes mantidos no rebanho & & & \\
$\quad$ Sim & 0,031 & 1,060 & $1,005-1,117$ \\
$\quad$ Não & & & \\
\hline
\end{tabular}

$\mathrm{RP}=$ Razão de Prevalência; $I C$ = Intervalo de Confiança.

Valor de $p$ do modelo (Omnibus Test) $=0,049$

Todas as variáveis estatisticamente significantes foram submetidas a análise de regressão de Poisson e concluiu-se que animais criados na mesorregião do Oeste Potiguar, em propriedades que não realizam quarentena, e mantém animais enfermos no rebanho, foram consideradas fatores de risco para infecção pelo VEV (Tabela 2).

Os fatores ambientais e de manejo diferiram muito entre as mesorregiões estudadas, o que pode influenciar numa maior exposição e consequente circulação do VEV. Comparando os dados das características de criação de cada uma dessas mesorregião Potiguares, observa-se maior concentração de animais submetidos ao sistema intensivo (57,5\% [231/402]) na mesorregião do Leste Potiguar quando comparada a mesorregião Oeste (6,9\% [28/407]). Equinos criados em baias individuais de forma intensiva podem reduzir o contato entre animais, vetores, fômites e ambiente contaminados, o que justificaria a menor ocorrência de equídeos soropositivos na mesorregião do Leste Potiguar.

Em contrapartida, o maior acesso dos equídeos as pastagens nas criações do Oeste Potiguar, aumentam a exposição ao VEV, principalmente em condições ambientais que propiciam a infecção, propagação e manutenção do vírus e de seus possíveis vetores, durante o contanto entre equinos ou outras espécies de animais susceptíveis (Arruda et al., 2015, Rozo-Lopez et al., 2018). Nessa mesorregião é comum a utilização dos equídeos no manejo do gado e a criação consorciada dessas espécies, o que pode aumentar o risco da presença do vírus, em especial, nas situações de compartilhamento de pastagens e mananciais entre diferentes rebanhos (Bezerra et al., 2018), com consequente transmissão cruzada (Cargnelutti et al., 2014). Apesar desse estudo ser realizado em equídeos, torna-se importante, para identificar as áreas de ocorrência do VEV, no caso da ocorrência de doenças vesiculares em animais biungulados, uma vez que é um dos diagnósticos diferenciais da Febre Aftosa (Arruda et al., 2015).

A transmissão entre locais e em grandes áreas geográficas é especulativa, porém acredita-se que envolva o movimento de insetos, por meio dos animais (pássaros) ou correntes de vento (Bennet et al., 2008), uma vez que, o VEV já foi isolado em Culicoides como Phlebotomus e Aedes (Lunkes et al., 2016) e experimentalmente em moscas (Urie et al., 2018).

Vetores biológicos parecem ser a principal fonte de transmissão do VEV, uma vez que foi relatado que cavalos com maior exposição a insetos, como os presentes nas pastagens, possuem maior risco de infecção (Urie et al., 2018). Essa teoria pode estar relacionada a presença de microabrasões, otimizadas em vegetações como as da região semiáridas do Nordeste, e a atração de insetos por lesões, que aumentariam a probabilidade e/ou a suscetibilidade a infecção. A disposição dos equídeos em pastagens também pode expô-los a outra fonte de infecção hipotética, que é a presença de material vegetal contaminado.

Ainda que, a transmissão do VEV seja mais comum em zonas tropicais e subtropicais no final da estação chuvosa ou início da estação de seca, alguns surtos de VEV-NJ e VEV-IN 1 tem ocorrido nos EUA em regiões mais secas, distantes do fluxo de água, sugerindo uma possível mudança nas espécies primárias de vetores (Rozo-Lopez et al., 2018), o que poderia ter ocorrido também na mesorregião Oeste do Potiguar, cujo clima é mais seco.

Essas diferenças climáticas e de criação, tornam-se mais relevantes quanto avaliamos o manejo sanitário das duas mesorregiões, e observamos elevadas taxas de equídeos expostos a situações de negligência quanto ao controle sanitário, tais como, a não realização de quarentena (92,3\% [747/809]) e isolamento de animais enfermos (91\% [736/809]), predispondo a introdução e manutenção do agente nas criações.

O manejo sanitário apresenta forte influência na ocorrência da $\mathrm{EV}$, uma vez que, o contato direto de animais susceptíveis com animais infectados ou fômites (bebedouros, comedouros, baia, etc.), parecem desempenhar um papel muito importante na transmissão (Zimmer et al., 2013).

Urie et al. (2018) avaliando fatores de risco para VEV observaram que cavalos sadios expostos ao mesmo ambiente que cavalos infectados apresentavam maiores chances de se contaminarem comparados com cavalos sadios que não mantinham contato direto os doentes $(\mathrm{OR}=17,6, \mathrm{IC} 95 \%=1,8-71,2)$, corroborando os achados nesse estudo ao observar que animais enfermos mantidos no rebanho e/ou que não eram submetidos a quarentena predispõe a presença do VEV.

\section{Conclusão}

Com base nos resultados obtidos, foi identificado a presença de anticorpos anti-VEV Indiana 2 e 3 em equídeos, e consequente circulação do VEV no estado do Rio Grande Norte, devendo-se ter atenção a exposição dos animais as pastagens em períodos de umidade, uma vez que as falhas de manejo sanitário identificadas, propiciam a introdução, disseminação e manutenção do vírus no ambiente. Dessa forma, devem ser instituídas medidas de controle e prevenção com ênfase em criações que adotam os sistemas extensivo e semi-intensivo. 


\section{Referências}

ALLENDE, R.; GERMANO, P.M.L. Comparison of virus neutralization and enzyme-linked immunosorbent assay for the identification of antibodies against Vesicular Stomatitis (Indiana 3) Virus. Revue Scientifique et Technique, v.12, n.3, p.849-855, 1993.

ARRUDA, R.C.N.; SEGUNDO, J.M.F.; SOARES, B.A.; MARTINS, N.R.S.; BARÇANTE, T.A.; BARÇANTE, J.M.P. Investigação epidemiológica de estomatite vesicular por achados clínicos em bovinos e equinos no estado do Maranhão. Pesquisa Veterinária Brasileira, v.35, n.5, p.391-395, 2015.

BENNETT, K.E.; HOPPER, J.E.; STUART, M.A.; WEST, M.; DROLET, B.S. Blood-feeding behavior of Vesicular Stomatitis Virus infected Culicoides sonorensis (Diptera: Ceratopogonidae). Journal of Medical Entomology, v.45, n.5, p.921-926, 2008.

BEZERRA, C.S.; CARGNELUTTI, J.F.; SAUTHIER, J.T.; WEIBLEN, R.; FLORES, E.F.; ALVES, C.J.; CLEMENTINO, I.J.; SANTOS, C.; AZEVEDO, S.S. Epidemiological situation of Vesicular Stomatitis Virus infection in cattle in the state of Paraíba, semiarid region of Brazil. Preventive Veterinary Medicine, v.15, n.160, p.68-75, 2018.

CARGNELUTTI, F.J.; OLINDA, R.G.; MAIA, L.A.; AGUIAR, G.M.N.; NETO, E.G.M.; SIMÕES, S.V.D.; LIMA, T.G.; DANTAS, A.F.M.; WEIBLEN, R.; FLORES, E.F.; RIET-CORREA, F. Outbreaks of Vesicular Stomatitis Alagoas virus in horses and cattle in Northeastern Brazil. Journal of Veterinary Diagnostic Investigation, v.26, n.6, p.788-794, 2014.

DE STEFANO, E.; ARAÚJO, W.P.; PASSOS, E.C.; PITUCO, E.M. Estomatite Vesicular: revisão bibliográfica. Arquivos do Instituto Biológico, v.69, n.3, p.127-133, 2002.
HOSMER D.W.; LEMESHOW S. 1987. Applied logistic regression. 2ed. New York: Wiley-Intersience Publication.

IBGE - Instituto Brasileiro de Geografia e Estatística. Panorama 2019.

IBGE - Instituto Brasileiro de Geografia e Estatística. Ranking Rebanho efetivo do estado do Rio Grande do Norte. 2017.

LUNKES, V.L.; TONIN, A.A.; MACHADO, G.; CORBELLINI, L.G.; DIEHL, G.N.; SANTOS, L.C.; BEZERRA, C.S.; AZEVEDO, S.S.; PEQUENO, N.B.; SILVA, A.M.; WEIBLEN, R.; FLORES, E.F. Antibodies against Vesicular Stomatitis Virus in horses from Southern, Midwestern and Northeastern Brazilian States. Ciência Rural, v.46, n.8, p.1424-1429, 2016.

OIE - Organização Mundial de Saúde Animal. Manual of Diagnostic Tests and Vaccines for Terrestrial Animals 2018.

ROZO-LOPEZ, P.; DROLET, B.S.; LONDOÑO-RENTERIA, B. Vesicular Stomatitis Virus transmission: a comparison of incriminated vectors. Insetos, v.9, n.4, p.190, 2018.

URIE, N.J.; LOMBARD, J.E.; MARSHALL, K.L.;

DIGIANANTONIO, R.; PELZEL-MCCLUSKEY, A.M.; MCCLUSKEY, B.J.; TRAUB-DARGATZ, J.L.; KOPRAL, C.A.; SWENSON, S.L.; SCHILTZ, J.J. Risk factors associated with clinical signs of vesicular stomatitis and seroconversion without clinical disease in Colorado horses during the 2014 outbreak. Preventive Veterinary Medicine, v.1, n.156, p.28-37, 2018.

THRUSFIELD, M.V. Veterinary epidemiology. $3^{\mathrm{a}}$ ed. Oxford: Blackwell Science Ltd., 2007. 610p

ZIMMER, B.; SUMMERMATTER, K.; ZIMMER, G. Stability and inactivation of vesicular stomatitis virus, a prototype rhabdovirus. Veterinary Microbiology, v.162, n.1, p.78-84, 2013. 